NASA Technical Memorandum 100811

AIAA-88-2348

\title{
The Effects of Rotational Flow, Viscosity, Thickness, and Shape on Transonic Flutter Dip Phenomena
}

T.S.R. Reddy

The University of Toledo

Toledo, Ohio

Rakesh Srivastava

Georgia Institute of Technology

Atlanta, Georgia

and

Krishna Rao V. Kaza

Lewis Research Center

Cleveland, Ohio

Prepared for the

29th Structures, Structural Dynamics and Materials Conference cosponsored by the AIAA, ASME, ASCE, and AHS

Williamsburg, Virginia, April 18-20, 1988 
THE EFFECTS OF ROTATIONAL FLOW, VISCOSITY, THICKNESS, AND SHAPE ON TRANSONIC FLUTTER DIP PHENOMENA

\author{
T.S.R. Reddy \\ The University of Toledo \\ Toledo, Ohio 43606 \\ Rakesh Srivastava \\ Georgia Institute of Technology \\ Atlanta, Georgia 30332 \\ and \\ Krishna Rao V. Kaza \\ National Aeronautics and Space Administration \\ Lewis Research Center \\ Cleveland, Ohio 44135
}

Abstract

The transonic flutter dip phenomena on thin airfoils, which are employed for propfan blades, is investigated using an Integrated Eulerl

Navier-Stokes code and a two degrees of freedom

typlcal section structural model. As a part of

$m$ the code validation, the flutter characteristics

g of the NACA 64A010 airfoll are also investigated.

i In addition, the effects of artificlal dissipation

models, rotational flow, initial conditions, mean

angle of attack, viscosity, alrfoll thickness, and shape on flutter are investigated.

The present results obtained with a Euler code for the NACA $64 A 010$ airfoll are in reasonable agreement with published results obtalned by using transonic small disturbance and Euler codes. The two artificial dissipation models, one based on the local pressure gradient scaled by a common factor and the other based on the local pressure gradient scaled by a spectral radius, predicted the same flutter speeds except in the recovery region for the case studied.

The effects of rotational flow, Inttial conditlons, mean angle of attack, and viscosity for the Reynold's number studled seem to be negliglble or small on the minima of the flutter dip. However, they have significant effect on the flutter boundary away from the dip.

The flutter dip shifts towards higher Mach number as the thickness decreases for symmetrlcal alrfolls, other parameters being the same. This is in direct relation to the location and strength of the shock. The flutter boundary for a thin cambered airfoll (propfan airfoll) showed that the effect of camber is nullifled by the effect due to reduction in thickness and showed a relatively low transonic dip.

The flutter boundary of a simulated SR5 propfan typical section model showed a very low transonic flutter dip. However, further studies with varying mean angles of attack and mass ratio are required to better understand the transonic flutter dip phenomena of highly swept propfans.

- NASA Resident Research Associate.
NOMENCLATURE

distance of elastic axis from the or Igin

speed of sound

semichord

damping coefficlent in plunging

pressure coefficlent

damping coefficlent in pitching

chord

lift coefficlent

moment coefficient about elastic axis

total energy of the fluid per unit volume

plunging (bending) displacement, positive downward

polar mass moment of Inertia

Jacobian of transformation

plunging spring constant

pitching spring constant

Mach number

mass per unit length

generalized force in plunging

generalized force in pitching

Reynold's number based on chord

radius of gyration about elastic axis

radius of gyration about center of gravity

static unbalance, $m b x_{\alpha}$ 


\begin{tabular}{|c|c|}
\hline$t$ & time \\
\hline $\bar{t}, \tau$ & nondimenstonal time, $t a_{\infty} / c$ \\
\hline$u, v$ & $\begin{array}{l}\text { Cartesian velocities normalized by the } \\
\text { speed of sound }\end{array}$ \\
\hline V & resultant velocity \\
\hline$V_{F}$ & flutter velocity \\
\hline $\bar{x}$ & $\begin{array}{l}\text { distance measured from leading edge to } \\
\text { tralling edge, normallized by chord }\end{array}$ \\
\hline$x, y$ & Cartesian coordinate system \\
\hline$x_{\alpha}$ & $\begin{array}{l}\text { distance between elastic axis and cen- } \\
\text { ter of gravity }\end{array}$ \\
\hline$\alpha$ & $\begin{array}{l}\text { pitching (torsion) displacement, posi- } \\
\text { tive nose up }\end{array}$ \\
\hline$\alpha_{\mathfrak{a}}$ & angle of attack, deg \\
\hline$n$ & $\begin{array}{l}\text { normal direction of transformed coordi- } \\
\text { nate system }\end{array}$ \\
\hline$\mu$ & mass ratio \\
\hline$\zeta_{h}$ & $\begin{array}{l}\text { critical damping coefficient in } \\
\text { plunging }\end{array}$ \\
\hline$\zeta_{\alpha}$ & $\begin{array}{l}\text { critical damping coefficient in } \\
\text { pitching }\end{array}$ \\
\hline$\xi$ & $\begin{array}{l}\text { chordwise direction of transformed } \\
\text { coordinate system }\end{array}$ \\
\hline$\rho$ & alr density \\
\hline$\omega_{h}$ & uncoupled plunging frequency, $\sqrt{k_{h} / m}$ \\
\hline$\omega_{\alpha}$ & uncoupled pitching frequency, $\sqrt{k_{\alpha} / I_{\alpha}}$ \\
\hline \multicolumn{2}{|c|}{ Superscripts } \\
\hline() & $d() / d t$ \\
\hline()$^{\prime}$ & $d() d \bar{t}$ \\
\hline$n-1, n, n+1$ & time levels \\
\hline
\end{tabular}

\section{Introduction}

The requirements of high aerodynamic efficlency and low noise in the operating range of transonic flow has resulted in thin ( 2 to 4 percent thick), highly swept and twisted blades for propfans. These blades operate at moderate to large mean angles of attack. In wind tunnel tests of a ten-bladed, highly swept SR5 propfan model, conducted at NASA Lewis Research Center, the blades have fluttered at transonic tip Mach numbers at sea level conditions. The aeroelastic characteristics of this model were investlgated in Refs. 1 to 3 by using a two-dimensional linear subsonic unsteady cascade aerodynamic theory with a correction for blade sweep. The correlation between theory and experiment varled from poor to good, depending on the test parameters. To further understand the physics of the flutter phenomena and to validate the recently developed linear cascade aeroelastic models for three-dimensional subsonic flow condi- tlons, correlative studies were continued in Refs. 3 to 6 which showed good agreement between theory and experiment. However, because of the limitations of the employed linear subsonic unsteady cascade aerodynamic models, the investigations in Refs. 1 to 6 were unable to throw any light on the effect of nonlinear transonic flow on flutter characteristics of swept, thin blades in general, and of the SR5 propfan model in particular.

The present investigation was initiated to help address the nonlinear effects on the flutter of a propfan in the transonic flow regime by using a step-by-step approach. In the first step, the investigation is restricted to an isolated airfoll with two degrees of freedom. The isolated airfoil section is selected as the section at 75 percent span of a thin swept propfan blade. The unsteady aerodynamic loads on the isolated alrfoll are calculated by using a two-dimensional Euler/Navierstokes solver. This aerodynamic model is selected since adequate three-dimensional, unsteady. cascade, transonic aerodynamic models for rotating propfan blades are not avallable. Even though the propfan blades are in a cascade, which has a destabillizing effect on flutter characteristics, the cascade effects are neglected in this investigation: since the major goal of this paper is to understand the physics behind the flutter dip phenomena of thin, swept isolated airfoils. As a byproduct of the code validation calculations, the effects of blade shape, thickness, mean angle of attack, initial conditions, rotational flow, and viscosity on the transonic flutter characteristics of a thick alrfoll are also investigated.

The approach being used for the flutter analysis is the simultaneous integration of structurefluid dynamics equations. The loads determined from solving the fluld dynamic equations are used as input to the structural dynamic equations. The resultant deflections are then used as input to the fluld dynamic equations to determine the loads again. If the amplitude of the deflections grow in time, then flutter is said to have occurred. In all methods of flutter analyses, the difference lies mainly in the prediction of aerodynamic loads.

Early published research on the effects of transonic flow on propfan blade, or propfan airfoil flutter characteristics is nonexistent. However. considerable research $7-24$ is being conducted on flutter characteristics of airfoils and aircraft wings in transonic flow. Published results20-24 show that there is a considerable amount of reduction in flutter speed in the transonic flow regime for highly swept blades when compared to the flutter speed predicted by linear theorles. This reduction has been called transonic flutter dip. This transonic flutter dip has been investigated by using transonic small disturbance (TSD)

theory; $\{0,20,21$ modified strip analys is method:22 the Euler equations; 23 and the Navier-Stokes equations. 24 Many of these methods, along with flutter results, are reviewed in Ref. 25.

The small disturbance theory and full potential flow theorles fall to take into account the rotationality of the flow, which could be significant for regions where curved shocks exist. Furthermore, potential flow theory may give multiple steady-state solutions at a given flight condition If the free stream Mach number is sufficiently 
high. Even though the flutter boundarles have been predicted using these methods, the question has always been asked, how strong are the effects of rotational flow, shock location, and shock strength on the prediction of flutter boundarles? These effects can only be studied by using elther the Euler equations or the Navier-Stokes equations.

Flutter calculations using Euler equations were presented in Ref. 23. The study showed significant differences in the flutter boundaries, compared with those obtalned using TSD theories, when the steady shocks are strong and at or near the trailing edge. Reference 16 presented steady and unsteady pressure calculations using Euler equations, and concluded that "the interaction of shock with the boundary layer is strong enough to alter the airfoll pressure distribution substantially." The interaction of a shock and boundary layer may lead to boundary layer separation resulting in a flow condition which is totally beyond the capabllity of Euler equations. Also, the Euler equations do not show the effect of viscosity on the flutter boundary. This means that for most accurate prediction of the aerodynamic loads and the flutter boundary, solution of the Navier-stokes equations is needed. It should al so be noted here that the calculations done so far in the published ilterature have been with 6 to 12 percent thick alrfolls. With the advent of propfans, consisting of 2 to 4 percent thlck airfolls, an investigation is required for thinner alrfolls.

In the present paper, the Euler/Navier-Stokes flow solver, which is described in Ref. 26, and coupled to a binary structural dynamic model in Ref. 24, whll be applled first to study the effects of rotational flow, initial conditions, mean angle of attack. viscosity, blade shape, and thlckness on the transonic flutter characteristics of a swept NACA $54 A 010$ airfoll with the structural parameters given in Ref. 20. Next, the coupled binary structural dynamic model flow solver will be applled to a thin, swept SR5 propfan blade section to study its transonlc flutter characteristics. It is to be mentloned here that the artificlal dissipation model used in Ref. 24 was based on the local pressure gradlent scaled by a constant factor. Recently, efforts are belng made 27 to incorporate a second dissipation model in this code. This model is based on the local pressure gradient scaled by a spectral radius. Preliminary results obtained using this model will also be presented for comparison.

\section{Aeroelastic Model}

A typlcal section model of a blade, as shown in Fig. i(a), is used for the flutter study. The typlcal section has two degrees of freedom, plunging $(h)$ and pitching $(a)$, positive as shown. The governing equations for this model are

$$
\begin{aligned}
& m \ddot{h}+S \ddot{\alpha}+C_{h} \dot{h}+K_{h} h=Q_{h} \\
& \ddot{h}+I_{\alpha} \ddot{\alpha}+C_{\alpha} \dot{\alpha}+K_{\alpha} \alpha=Q_{\alpha}
\end{aligned}
$$

where $m$ is the mass, $S$ is static unbalance, $C_{h}, C_{a}$ are structural damping parameters, $K_{h}$ and $K$ are the plunging and pitching spring constants, $Q_{h}^{\alpha}$ and $Q_{\alpha}$ are the generallzed forces, and ()$^{\prime}$ is $d() / d t$. Defining $\bar{h}=h / 2 b, x_{\alpha}=s / m b, r_{\alpha}^{2}=I_{\alpha} /$ $m b^{2}, \omega_{h}^{2}=K_{h} / m, \omega_{\alpha}^{2}=K_{\alpha} / I{ }_{\alpha}, c_{h}=2 \zeta_{h} \omega_{h} m$, and

$C_{\alpha}=2 \zeta_{\alpha} \omega_{\alpha} I_{\alpha}$, where $b$ is the semi-chord, $I_{\alpha}$ is the mass moment of inertia about the elastic axis, $\omega_{h}$ and $\omega_{\alpha}$ are the uncoupled plunging and pitching frequencles, $\zeta_{h}$ and $\zeta_{\alpha}$ are the critical damping factors in bending and torsion, Eq. (1), can be written as

$$
\begin{gathered}
\ddot{\bar{h}}+\left[\begin{array}{l}
x \\
\frac{\alpha}{2}
\end{array}\right] \ddot{a}+\left[2 \zeta_{h} \omega_{h}\right] \dot{\bar{h}}+\left[\omega_{h}^{2}\right] \bar{h}=\frac{Q_{h}}{2 m b} \\
{\left[\begin{array}{l}
x \\
\frac{\alpha}{2}
\end{array}\right] \bar{h}+\left[\frac{r}{2}\right]^{2} \ddot{\alpha}+\left[\frac{\zeta \alpha^{2} r^{2}}{2}\right] \dot{\alpha}+\left[\frac{\alpha \alpha}{2}\right]^{2} \alpha=\frac{\alpha}{4 m b^{2}}}
\end{gathered}
$$

The generalized forces, $Q_{h}$ and $Q_{\alpha}$ are related to the lift and moment coefficients, obtained from the aerodynamic code as follows:

$$
\begin{aligned}
& Q_{h}=-\frac{1}{2} \rho v^{2}(2 b) c_{1} \\
& Q_{\alpha}=\frac{1}{2} \rho V^{2}(2 b)^{2} c_{m}
\end{aligned}
$$

where $c$, is the lift coefficlent, and $c_{m}$ is the moment coefficient about the axis of rotation (elastic axis), $V$ is the resultant velocity and $\rho$ is the afr density. Defining, $\bar{t}=\operatorname{ta}_{\infty} /(2 b)$, and $V^{*}=V /\left(b \omega_{\alpha}\right)$, where $a_{\infty}$ is the speed of sound and substituting $\mathrm{Eq}$. (3) Into Eq. (2), the final aeroelastic equations can be written as

$$
\begin{aligned}
& \bar{h}+\left[\frac{x_{\alpha}}{2}\right]_{\alpha}^{\prime \prime}+\left[\frac{4 \zeta_{h} M \omega_{h}}{\left(V^{*} \omega_{\alpha}\right)} \bar{h}^{\prime}+\left[\frac{2 M \omega_{h}}{\left(V^{*} \omega_{\alpha}\right)}\right]^{2} \bar{h}=-\frac{2 c_{1} M^{2}}{\pi \mu}\right. \\
& {\left[\frac{x_{\alpha}}{2}\right]^{\prime \prime}+\left[\frac{r}{2}\right]^{2} \alpha+\left[\frac{\zeta{ }^{r^{2}}{ }^{\prime}}{V^{*}}\right]_{\alpha}^{\prime}+\left[\frac{M r}{V^{*}}\right]^{2} \alpha=\frac{2 c_{m} M^{2}}{\pi \mu}}
\end{aligned}
$$

where ()$^{\prime}=d() / d \bar{t}, M=V / a_{\infty}$, and $\mu$ is $\mathrm{m} / \pi p b^{2}$. For simplicity, the bar on $h$ and $t$ will be dropped for the rest of the paper.

An implicit time marching technique is used to solve $\mathrm{Eq}$. (4) in time. Let $n$ be the time level where the solution is known and $n+1$ is the time level where $h$ and $\alpha$ are sought. Then the first and second derivatives of $h$ (with simllar expressions for $\alpha$ ) are written as

$h^{\prime}=\frac{\left(h^{n+1}-h^{n}\right)}{\Delta t} ; h=\frac{\left(h^{n+1}-2 h^{n}+h^{n-1}\right)}{(\Delta t)^{2}}$

where $\Delta t$ is the time step in the marching procedure. Substitution of these finite difference derivatives for $h^{\prime}, h^{\prime \prime}, \alpha^{\prime}, \alpha^{\prime \prime}$ into Eq. (4) leads to a system of simuitaneous equations for $h$ and $\alpha$ at each time step.

The lift and moment coefficients $\left(c_{1}, c_{m}\right)$ in Eq. (4), are calculated by integrating the pressure distribution over the airfoll surface at each time step. The pressure is obtained by solving the unsteady, two-dimensional, Reynolds- averaged, compressible Euler or Navier-Stokes equations on a body-fitted coordinate system in strong conservation form using an alternate direction implicit (ADI) procedure. The formulation has been 
described in Ref. 26, and only a brlef outline is given here. All the calculations are performed in a body-fitted coordinate system $(\xi, \eta, \tau)$ which is mapped to the Cartesian coordinates $(x, y, t)$, Fig. I(b), according to the following one-to-one relationship:

$$
\begin{aligned}
& \xi=\xi(x, y, t) \\
& \eta=\eta(x, y, t) \\
& \tau=t
\end{aligned}
$$
given by

The Jacobian of the transformation $\mathrm{J}$ is

$$
J=\xi_{x} n_{y}-\xi_{y} n_{x}=\frac{1}{\left(x_{\xi} y_{n}-x_{n} y_{\xi}\right)}
$$

and the metrics of the transformation are given by the relationship:

$\xi_{x}=J y_{n} ; \xi_{y}=-J x_{n} ; \eta_{x}=-J y_{\xi} ; \eta_{y}=J x_{\xi}$

Once a grid has been constructed the metrics of the transformation can be evaluated numerically. Standard central differences were used to compute the quantities such as $x_{n}, y_{n}$, etc., and these quantities in turn were used in Eqs. (7) and (8) to compute $\xi_{x} . \xi_{y}$. etc. At the boundaries, threepoint one-sided differences were used to compute the metrics.

In the $(\xi, n, \tau)$ coordinate system, the twodimensional unsteady Navier-Stokes equations may be written as

$$
\hat{q}_{\tau}+\hat{F}_{\xi}+\hat{G}_{\eta}=\hat{R}_{\xi}+\hat{S}_{\eta}
$$

where

$$
\hat{q}=J^{-1}(\rho, \rho u, \rho v, e)
$$

and $\rho$ is the fluid density: $u$ and $v$ are the Cartesian components of fluid velocity; $e$ is the total energy of the fluid per unit volume. The quantities $\hat{F}, \hat{G}, \hat{R}$, and $\hat{S}$ are given by

$$
\begin{aligned}
& \hat{F}=\frac{\left(\xi_{x} F+\xi_{y} G+\xi_{\tau} q\right)}{J} \\
& \hat{G}=\frac{\left(n_{x} F+n_{y} G+n_{\tau} q\right)}{J} \\
& \hat{R}=\frac{\left(\xi_{x} R+\xi_{y} S\right)}{J} \\
& \hat{S}=\frac{\left(n_{x} R+n_{y} S\right)}{J}
\end{aligned}
$$

The terms $F$ and $R$ are the flux and viscous stress terms along the $x$-direction and $G$ and $S$ are likewlse the flux and viscous terms along the $y$-direction and are given as follows:

$$
\begin{aligned}
& F=\left(\rho u, \rho u^{2}+p, \rho u v, u(e+p)\right) \\
& G=\left(\rho v, \rho u v, \rho v^{2}+p, v(e+p)\right) \\
& R=\left(0, \tau_{x x}, \tau_{x y}, R_{4}\right) \\
& S=\left(0, \tau_{x y}, \tau_{y y}, S_{4}\right)
\end{aligned}
$$

The quantities $R_{4}$ and $S_{4}$ represent the dissipation of energy due to work done by the fluid in the $x$ - and $y$-directions respectively. The viscous stresses $\tau_{x x}, \tau_{x y}$, and $\tau_{y y}$ are related to the velocity gradients through Stokes hypothesis.

Since the governing equations, Eq. (9), are coupled and highly nonlinear, a stable and efficlent solution procedure is required. In the present work, the Beam-Warming algorithm, 28 as implemented by Steger, 29 was followed with modiftcations noted by Sankar and Tang. 26 The viscous terms are evaluated explicitiy to reduce the number of operations needed to solve the governing equations. A brief description of the solution scheme is given here.

The governing equations are written at a computational node $(i, j)$ in the following finite difference form:

$\frac{\Delta \hat{q}_{\mathfrak{i} \mathcal{j}}^{n+1}}{\Delta t}+\delta_{\xi} \hat{F}^{n+1}+\delta_{n} \hat{G}^{n+1}=\delta_{\xi} \hat{R}^{n}+\delta_{n} S^{n}-\varepsilon_{E} D^{n}$

where

$$
\Delta \hat{q}_{i j}^{n+1}=\hat{q}^{n+1}-\hat{q}^{n}
$$

The operators $\delta_{\xi}$ and $\delta_{n}$ are standard central difference operators. For example, the term $\delta \xi F$ if is the standard two point central difference formula given by $\left(F_{j+1} j-F_{j}-1, j\right) / 2$. $D_{i j}$ is an artificial dissipation term and is discussed in the next section.

The highly nonlinear terms $F$ and $G$ at the time level $(n+1)$ were expanded by a Taylor series about a previous time level $n$ as

$$
\begin{aligned}
& \hat{F}^{n+1}=\hat{F}^{n}+\left(\frac{\partial \hat{F}}{\partial \hat{q}}\right)^{n} \Delta \hat{q}^{n+1} \\
& \hat{G}^{n+1}=\hat{G}^{n}+\left(\frac{\partial \hat{G}}{\partial \hat{q}}\right)^{n} \Delta \hat{q}^{n+1}
\end{aligned}
$$

where $\partial \hat{F} / \partial \hat{q}$ and $\partial \hat{G} / \partial \hat{q}$ are 4 by 4 matrices which are the Jacoblans of the flux terms $\hat{F}$ and $\hat{G}$ with respect to $\hat{q}$.

In order to allow large values of the explicit dissipation coefficient $\varepsilon_{E}$ to be used without instability, and to allow the viscous terms to be treated explicitly, the following implicit dissipation terms were added to the left side of the difference Eq. (13).

$$
-\varepsilon_{I} J^{-1}\left(\delta_{\xi \xi}+\delta_{n \eta}\right) J \Delta \hat{q}^{n+1}
$$

The coefficient $\varepsilon$ was taken to be two to three times the explicit dissipation coefficient $\varepsilon_{E}$. A range of $\varepsilon_{E}$ values between 2 and 5 were used in the calculations.

The dissipative term, $D_{i f}$, is added to remove high-frequency errors in the solution at every time step, and to avold odd-even decoupling of the numerical solutions. Two models of introducing artificlal dissipation are avallable in the present code. In model I, 26 the dissipation term is written, in conservative form, as a combination of secand and fourth order dissipative terms. This model 
Is based on the local pressure gradient scaled by a constant factor. A sensor based on the second derlvative of pressure, turns the second order disslpation term in the vicinity of shocks and suppresses the fourth order dissipation terms. This sensing is followed only in the streamwise direction. A more detalled description of this model. and bench mark calculations are presented in

Ref. 26. This model, as pointed out in Ref. 30 . adds positive dissipation in certain regions and negative dissipation in other regions depending on the flow fleld gradients in that region, which may degrade the solution accuracy in some flow problems.

In model II, 27 the local pressure gradient is scaled with the spectral radius of the flux vector. The fourth order difference term is modifled in a way that it produces positive dissipative terms. This model is similar to the one presented in Refs. 31 and 32 and is being currently implemented in the present code by Wu. 27 Some preliminary test results will be given in the present paper.

Equation (13) may be written after the addition of the artificlal implicit dissipation terms given by Eq. (15), in the following operator form

$$
\begin{gathered}
{\left[I+\Delta t \delta_{\xi} \frac{\partial \hat{F}}{\partial \hat{q}}+\Delta t \delta_{n} \frac{\partial \hat{G}}{\partial \hat{q}}-\varepsilon_{I} J^{-1}\left(\delta_{\xi \xi}+\delta_{n n}\right) J\right]} \\
\Delta \hat{q}^{n+1}=R^{n}
\end{gathered}
$$

where

$R^{n}=-\Delta t\left(\delta_{\xi} \hat{F}+\delta_{n} \hat{G}\right)^{n}+\Delta t\left(\delta_{\xi} \hat{R}+\delta_{n} \hat{S}\right)^{n}-\Delta t \varepsilon_{E} D^{n}$

The left hand side operator of Eq. (16) was approximately factored into two small operators, leading to the following final form:

$$
\begin{aligned}
& {\left[I+\Delta t \delta_{\xi} \frac{\partial \hat{F}}{\partial \hat{q}}-\varepsilon_{I} \Delta t J^{-1} \delta_{\xi \xi} J\right]} \\
& x\left[I+\Delta t \delta_{n} \frac{\partial \hat{G}}{\partial \hat{q}}-\varepsilon_{I} \Delta t J^{-1} \delta_{n n}\right] \Delta \hat{q}^{n+1}+R^{n}
\end{aligned}
$$

Equation 18 may be solved through the inversion of two block tridiagonal matrix equations, one corresponding to the $\xi$-direction, and the other corresponding to the n-direction. In order to keep the flow solver simple, the boundary conditions on all the boundaries were explicitly updated after the interior points had been updated using Eq. (18).

The Baldwin-Lomax 33 eddy viscosity model is used to model the turbulent momentum and energy transfer. This is a two layer algebraic turbulence model with two algebralc equations in each layer.

Algebralc grld generation routines were included by Sankar and Tang 26 to make the code more portable. Both 0 - and $\mathrm{C}$-grlds can be generated. However, any grid can be overwritten for the alge-
bralc grid, for example, by a numerical grld. 34,35

The boundary condltions were treated expllcitily as follows: at the solid surface, the no sllp boundary conditions were enforced by setting the velocity of the fluld to that of the solid surface at every time step. At the solld surface, the normal derivative of the temperature and pressure were also set to zero. The use of the C-grid system introduces a cut between the alrfoil trailing edge and the downstream boundary. Along this cut, the flow properties were averaged from above and below. The body-fitted grids employed in this work were such that the far field boundarles were at least six chord lengths away. The flow properties at the far field boundarles were assumed to be undisturbed.

The Navier-Stokes solver described here may also be used to model inviscid rotational flows. This requires that the viscous terms in the NavierStokes equations be suppressed, and that the zero tangential velocity boundary condition at the solid surface be replaced by a nonzero value, obtained by extrapolating the tangential component of the fluid velocity from the interlor.

The code is expected to predict the flow field for arbitrary alrfolls for moderate angles of attack. a Mach number range from 0.1 to 1.2 , and a Reynolds number range from 100 to 107 . This code has been used to predict the dynamic stall characteristics for the NACA 0012 airfoll,26 transonic flow solutions, 36 and stall flutter characteristics for the NACA 0012 airfoll.24

\section{Results and Discussion}

This section presents the numerical results obtained with the deroelastic model described earlier. First, the code is validated with published results. Next, the effects of rotational flow, initial conditions, mean angle of attack, and shape and thickness on transonic flutter are investigated. Then transonic flutter calculations are done for the SRS propfan blade typical section model.

\section{Code Validation}

References 24,26 , and 36 presented selected validation cases with the present Euler/NavierStokes flow solver. These cases represented different alrfolls at different flow condtions. In those references, the dissipation model I, which was described earller was used. As a part of the validation study of the dissipation model II, descrlbed earller, the pressure distribution for RAE2822 airfoll is recalculated. The results are compared with those obtained in Ref. 36 with dissipation model I and the experimental data presented therein. Figure 2 shows the steady pressure distribution (pressure coefficlent, $-C_{p}$, versus nondimensional distance along the chord, $\bar{x}=0.5^{*}(x / b+1)$, see the coordlnate system in Fig. (a)) for the RAE 2822 airfoll at Mach number, $M=0.73$, angle of attack, $\alpha_{a}=2.79^{\circ}$; and Reynold's number, $\operatorname{Re}=6.5 \mathrm{million}$. The numerical results with both dissipation models and the experimental data show very good comparison. These comparlsons help to give confidence in the code and in the attempt at flutter calculations with the dissipation model II.

In order to establish the capability of the code for predicting the transonic flutter dip, the flutter boundary of the NACA $64 A 010$ afrfoil is obtained. The calculations are carried out using 
the Euler version of the code with both dissipation models. A 157 by 40 algebraic C-grid shown in Fig. 3 is used in the calculations. The structural parameters are those used in Ref. 20 and are given as case $A$ in Table 1. In Ref. 20, the wing geometric sweep is modeled by positioning the elastic axis ahead of the leading edge ( $a h=-2.0$, see Fig. I(a)).

To obtain the flutter boundary, a steady-state flow field solution is first obtained for $0^{\circ}$ mean angle of attack. The solution of the aeroelastic equations (Eq. (4)) is then started at an assumed nondimensional flutter speed, $V^{\star}\left(=V /\left(b \omega_{\alpha}\right)\right.$, by prescribing the inltial conditions, $h(0), \alpha(0), h^{\prime}(0)$. and $\alpha(0)$. If the amplitude of oscillation of the resulting transient solution increases (decreases). the value of $V^{*}$ is reduced (increased) and the transient solution is again calculated. The critical flutter speed $\left(V_{F}\right)$ is obtained by linearly interpolating the logarithmic decrement of the amplitude of oscillations for two different but close values of $V^{*}$ (one giving oscillations with increasing amplitude and the other giving osclllatlons with decreasing amplitude). The flutter boundary is presented as a variation of the flutter speed index $\left(V^{*} F / \sqrt{\mu}\right)$ versus Mach number $(M)$.

The results obtained for the NACA 64A010 airfoll are compared with published results $10,\{1,2\}, 23$ in Fig. 4. Refs. 10,11, and 21 used transonic small disturbance (TSD) theory and Ref. 23 used Euler equations in the calculations. In this comparison, differences due to grids, numerical schemes, artiflctal viscosity, etc., employed in the published results are not considered but only the flutter boundaries are compared. In the present calculations, the initial conditions, $\alpha(0)=0.1^{\circ}$, with zero $h(0), h^{\prime}(0)$, and $\alpha(0)$ are used. The comparison shows that all of the codes $\{0,11,21,23$ qualltatively predict the transonic dip.

For Mach numbers between 0.7 and 0.82 , the flutter speeds predicted by the present Euler code are less than the corresponding values from Refs. 10, 11, 21, and 23. For Mach numbers between 0.82 and 0.87 the fiutter speeds predicted by all the codes are in good agreement. These differences can be explained partly by inspection of the pressure distribution over the airfoll. For a Mach number of 0.8 , the pressure distribution $\left(C_{p}\right)$, showed a shock appearling near the mid chord. This shock travels towards the trafling edge and increases in strength as the Mach number Increases. The ISD theorles are not able to model the effect of rotational flow downstream of the shock which could be signiflcant in some cases. Since the shock is almost near the mid chord, the flow is rotational over a reasonably large surface. This effect on a considerably large surface is totally neglected by the TSO codes which could result in a higher flutter boundary. Thus the difference between the flutter speeds calculated by using the Euler code and ISD codes in this region may be attributed to rotational flow and entropy effects behind shock. However for Mach numbers between 0.85 and 0.88 , the shock is almost near the trailling edge reducing the surface over which the flow is rotational. Then the calculations with Euler code shows same accuracy as of TSO codes. This could explain the very good compartson by all the codes between $M=0.85$ and 0.88 .
However, the transonic recovery portion of the flutter boundary predicted by the Euler codes differs from those predicted by codes based on TSO theory. The recovery predicted by Euler codes occurs at a higher Mach number compared to the one predicted by TSD codes. Also, the Euler code of Ref. 23 predicts the recovery to be at a higher Mach number compared to the present Euler code. Beyond $M=0.88$, the shock strength is sufficiently high enough to induce separation. The Euler and TSD codes fall to model separated flow behind shocks and predict qualitatively the same flutter boundary beyond $M=0.88$.

Also, there are significant qualitative differences in the recovery region of the flutter boundary obtained by the two dissipation models avallable in the present Euler code. The dissipation model I predicts a flutter boundary which folds over to provide upper boundaries. For a Mach number of 0.9 , three boundarles are observed. This compares qualitatively with the boundaries obtained in Refs 10, 11 , and 23. Whereas no such folding over of the boundary is observed when dissipation model II is used. Between Mach numbers of 0.88 and 0.9 the flutter boundary jumps considerably, and is almost the same as the third boundary obtained with dissipation model $I$. This has also been observed by Isogal. 21 Again, this difference can be explained by observing the pressure distribution obtalned with the two dissipation models. The pressure distributions obtained at $M=0.9$ with the two dissipation models are shown in Fig. 5. Both models show considerable differences with regard to the shock location and shock strength. The dissipation model II predicts the shock to be closer to the tralling edge than that predicted by dissipation model I. This may be the reason for the difference observed in the recovery region with these models.

Figure 6 shows a typical transient response solution. Figure $6(a)$ shows the transient response for a point below the flutter speed and Fig. $6(b)$ shows the response for a point above the flutter speed. In both the responses, the amplitude of $h$ is larger than that of $\alpha$, Indicating possible bending mode instability.

The above comparisons for the NACA 64A010 help to glve confidence in the code for investigation of the flutter dip phenomena for other airfolis. It also shows the importance of the accurate prediction of the shock strength and position.

The code is now applied to study the effects of the following: (1) initial conditions,

(2) mean angle of attack, (3) viscosity, and (4) thickness and shape. Dissipation model I is used in all the calculations.

Effect of initial conditions. To study the effect of initial conditions, the initial condition on $\alpha(0)$ is increased from $0.1^{\circ}$ to $4^{\circ}$. The flutter boundary for $4^{\circ}$, together with that for $0.1^{\circ}$, is shown th Fig. 7. For a Mach number of 0.8 the flutter speed for $4^{\circ}$ decreases by approximately 30 percent. This has also been observed in Ref. 23. However, for Mach numbers of 0.85 and 0.88 there does not seem to be any significant change in flutter speeds (less than 10 percent). This again seems to be due to the position of the shock. Since the shock is near the trailing edge of the airfoil, the effect of rotation does not 
seem to be of much significance. The results show that the initial conditions coupled with transonic flow nonlinearities have significant effects on the flutter characteristics in the transonic Mach number range, but negligible effect on the minima of the transonic dip.

Effect of mean angle of attack. The effect of mean angle of attack was studied by starting the solution of the aeroelastic equations (Eq. (4)) at different steady flow field conditions. In the present study, the steady flow fleld is calculated at two degrees of angle of attack, instead of $0^{\circ}$. for Mach numbers $0.75,0.8,0.85$, and 0.88 . The initial condition, $\alpha(0)$, is again $0.1^{\circ}$. These results are also included in Fig. 7. The transonic dip moves to left since the shock occurs at lower Mach numbers. For Mach number equal to 0.8 , the reduction in flutter speed index is almost 50 percent. This was also observed by Edwards, et al. 10 However, the shifting of the flutter boundary does not seem to be as much as observed in Ref. 10. Agaln, the effect of the mean angle is negligible at the minima of the dip.

Effect of viscosity. The flutter boundary calculations to study the effect of viscosity are very expensive. The requlred computational time is almost an order of magnitude higher than that for the Euler case. Hence the effect was studied only for a Reynold's number of $12 \mathrm{~m} f 11$ ion. These results are also shown in Fig. 7. For this case again the flutter boundary near the dip shifts down by less than 5 percent. This shift could be attributed to change in grid spacing near the alrfoll since a very fine grid is required near the airfoll for the viscous case. The only significant difference was that even with the dissipation model I, there was no upper boundary observed. The effect of viscosity seems negligible for the Reynold's number studled here. However, studles at a lower Reynold's number are in progress.

Effect of shape and thickness. The effect of shape and thickness on the flutter boundary is studied next. Four NACA 16-series alrfolls with the same structural dynamic parameters as those used for the NACA $64 A 010$ airfoll are considered for the study (see Table 1. case A). This serles of airfolls is selected because these airfolls are used on current propfan designs. For example, the SR5 propfan has 16-serles alrfoll sections on the outer 45 percent of the span. The alrfoll sections vary in thickness and camber. The section selected for the present analysis is 2.6 percent thick and has a design lift coefficlent of 0.13 . Therefore, for the study of shape and thickness, the airfolls selected are 16-010, 16-004, 16-(1.3)(04), and $16-(1.3)(2.6)$. Here the first two diglts specify the series, the next digit indicates the amount of camber expressed in terms of the design lift coefficient in tenths, and the last two digits specify the thickness to chord ratio in percent chord. The first three airfolls are included for a step-bystep verification of the code and to applications for thin airfolis. Again, an algebrale C-grid of 157 by 40 is used.

The flutter boundarles for the selected alrfolls are compared in $\mathrm{Fig}$. 8. Comparison of the results for the NACA 16-010 and the NACA 16-004 a)rfolis show that the transonic dip shifts to the right for the latter airfoll. This is due to a decrease in thickness which delays the formation of the shock to higher Mach numbers. Because of smaller thickness, the shock strength is also small relative to that of NACA 16-010. This results in a smaller jump in the flutter boundary in the recovery region. For the same Mach number, the NACA 16-004 airfoll has a shock appearing behind that of the NACA 16-010 airfoil which results in a smaller region of rotational flow for the NACA 16-004 airfoil. The combined effect of the shock location and shock strength, and rotational flow is to lower the boundary for the NACA 16-010 as compared to that of the NACA 16-004 for the same Mach number. The flutter boundaries calculated up to $M=0.9$ for the NACA $64 A 010$ and the NACA 16-010 airfolls did not show any difference, indicating thickness has more effect on the flutter boundary than the shape.

The flutter boundary obtained for the NACA $16-(1.3)(04)$ is also shown in $\mathrm{F} / \mathrm{g} .8$. The pressure distribution curves, not shown here, for this airfoll showed a shock at a Mach number equal to 0.85 , which resulted in a drop in the flutter speed index compared to that for the NACA 16-004 airfoll. The shock is at the tralling edge beyond $M=0.88$, and the flutter speed index starts increasing again. The similarity of the flutter boundary curve with that of the NACA 16-004 airfoil is consistent with the observation that the camber effect is equivalent to the effect of initial angle of attack for the NACA $16-(1.3)(04)$ airfoll.

In Fig. 8, the flutter boundary obtained for the NACA $16-(1.3)(2.6)$ airfoil (the propfan airfoll) is also shown. A dip in the flutter boundary can be seen near $M=0.925$. There after the flutter speed index starts increasing. It is interesting to note that the flutter boundary between Mach numbers 0.85 and 0.95 is almost simliar to that obtained for the NACA 16-004 airfoll. This is due to the fact that the reduction in the flutter speed index due to camber, like that for the NACA

16-(1.3)(04) airfoll, is compensated by a decrease in thickness. Between Mach numbers 0.75 and 0.85 , the flutter boundaries for the NACA 16-004 and the NACA 16-(1.3)(2.6) alrfolls show the effect due to thlckness, as was observed for the NACA 16-010 and the NACA 16-004 airfolls. A typical response for the NACA 16-004 is shown in Fig. 9. Figure 9(a) shows the transient response for a point below the flutter speed, and Fig. 9(b) shows the response for a point above the flutter speed. In both responses, the amplitude of $h$ is larger than that of $\alpha$, indicating possible bending mode instablitity.

The comparison of the results from the four airfolls shows that (1) for symmetric airfolls, the transonic dip moves towards higher Mach numbers as thickness to chord ratio decreases, (2) for the thin cambered airfoil studied here, the camber effects are nullified by the effects due to reduction in thickness, and the flutter boundary is similar to a thick symmetric airfoll of the same series, and (3) the flutter characteristics strongly depend on the shock location and shock strength.

After establishing confidence in the code, it was applied to investigate the flutter characteristics of a simulated SR5 propfan blade. 
Flutter Characteristics of a Simulated SR5 Propfan Blade

A typical section model is constructed which simulates the structural properties, mode shapes, and coupled frequencles of the SR5 propfan. LI near subsonic isolated airfoil theory 37 is used in simulating the typical section model. The rotation axis (elastic axis) and the uncoupled bending and torsional frequencies are chosen such that the mode shapes and coupled frequencles are close to those calculated for a SR5 propfan blade using NASTRAN analys 15 . The selected properties are shown in Table 1 , case $B$. It should be noted here that the frequency ratio is almost equal to one as in case $A$, studied earlier, and the mass ratlo is approximately twice that of case $A$. For the structural properties selected, the calculated flutter Mach number and flutter reduced frequency are 0.875 and 0.17 . The corresponding experimental 1 values are 0.88 and 0.17 respectively.

The flutter boundary obtalned using the present Euler code with dissipation model I is shown in Fig. 10. The flutter boundary obtalned with linear isolated blade theory is also shown in Fig. 10 along with the velocity index curve ( $V /\left(b \omega_{\alpha} \quad \mu\right)$ versus $M$ ) for this typical blade. The present Euler code gives a flutter Mach number of 0.845 . This value is about 4.5 percent less than that obtained from SR5 propfan experiment. The prediction of lower flutter Mach number by the present Euler code may be due to the following reasons: (1) the limitation of the typlcal structural dynamic model employed to simulate the SR5 propfan and (2) no structural damping is included in the present analysis.

Figure 10 shows that the flutter speed index drops as the Mach number increases up to $M=0.9$, thereafter, it starts recovering, showing a very low transonic flutter dip for SR5 propfan blade. The Euler code predicts almost the same flutter boundary as the linear isolated blade theory. However, a much more pronounced transonic dip is expected when the following aspects are considered. The above calculations are made at zero mean angle of attack. In a real situation, the propfan is at a mean angle of attack whlch may cause transonlc flutter dip. The mass ratlo used is 115 , whlch is higher than for the present composite propfans having the mass ratio of the order of 33 to 60 . This low mass ratlo may cause transonic flutter dip which needs further investigation. The cascade effects which are found to have destabllizing effect on flutter in subsonlc flow, may also effect the transonic dip.

The following points support the above points when the flutter boundary obtained for the NACA $16-(1.3)(2.6)$ airfoll in Figs. 8 and 10 are compared. In Fig. 8, a relatively large dip is seen for the same alrfoll section. Here the mass ratio is 60 . which is about 48 percent less than that used for SRS propfan blade typical section in Fig. 10. Also, the elastic axis position is one semichord length in front of the leading edge compared to that used for SR5 propfan blade typical section. Since here only an attempt is made to simulate a SR5 propfan, these structural propertles need to be improved for correct prediction of flutter boundary and correlation with experiment in transonlc flow for thin highly swept propfans.

\section{Conclusions}

An Euler/Navier-Stokes flow solver is used to obtain the flutter boundaries for a typical section structural model with several airfoll sections. The application of the code for predicting transonic flutter characteristics of thick and thin airfolls is demonstrated. Based on this study, the following conclusions are drawn.

1. The rotational flow effects behind the shock have a strong effect on the transonic flutter speed depending on the chordwise location of the shock. The neglect of rotational flow effects results in predicting a higher flutter speed.

2. The two dissipation models employed, one based on the local pressure gradient scaled by a constant factor and the other based on the local pressure gradient scaled by spectral radius, predicted the same flutter boundary up to the transonlc dip for a thick alrfoll. However, in the recovery region, the boundaries predicted by these models are different.

3. The effects of initial conditions, mean angle of attack, and viscosity for the Reynold's number studled on the minima of the transonic dip seems negligible. However, they have a significant effect away from the dip.

4. The blade thickness and shape dictate the location and strength of the shock, there by affecting the flutter boundary. The transonic dip shifts to higher Mach numbers for symmetric airfolls with decreasing airfoll thickness to chord ratio. The flutter boundary, for relatively thin cambered alrfolls studied here, showed a relatively low transonic dip compared to a symmetric thick airfoll.

5. The predicted flutter Mach number for a simulated SR5 propfan blade 15 about 4.5 percent less than that obtained by experiment. This difference is attributed to the simplified aeroelastic model used in the present analysis. The flutter boundary showed a very low transonic dip. Further studies are needed to investigate the effects of mean angle of attack, mass ratio, and elastic axis position on the transonic flutter of highly swept composite propfans.

\section{Acknowledgments}

During the course of this investigation, the first author has been supported by NASA Grant NSG-3139 and the second author by NAG 3-730. The authors would like to thank Prof. N.L. Sankar, and Mr. J.C. Wu of Georgla Tech and Mr. Dennis Huff of NASA Lewis Research Center for many helpful discussions.

\section{References}

1. Mehmed, O., Kaza, K.R.V., Lubomsk1, J.F., and Klelb, R.E., "Bending-Torsion Flutter of a Highly Swept Advanced Turboprop," NASA TM-82975, 1982.

2. Turnberg, J.E., "Classical Flutter Stability of Swept Propeliers, " AIAA Paper 83-0847. May 1983. 
3. Elchuri, V. and Smlth, G.C.C., "Flutter Analysis of Advanced Turbopropellers," AIAA Journal. Vol. 22, No. 6, June 1984, PD. $801-802$.

4. Mehmed, O. and Kaza, K.R.V., "Experimental Classical Flutter Results of a Composite Advanced Turboprop Mode 1," NASA TM-88792, 1986.

5. Wllllams, M.H. and Hwang, C., "Three Dimensional Unsteady Aerodyanmics and Aeroelastlc Response of Advanced Turboprops," 27 th Structures, Structural Dynamics and Materlals Conference, Part 2, AIAA, New York, 1986, pp. 116-124.

6. Kaza, K.R.V., Mehmed, O., Narayanan, G.V., and Murthy, D.V. "Analytical Flutter Investigation of a Composite Propfan Model." 28th Structures, Structural Dynamics and Materla 15 Conference, Part 2A, AIAA, New York, 1987, pp. 84-97. (NASA TM-88944).

7. Ballhaus, W.F. and Goorjlan, P.M., "Computation of Unsteddy Transonic Flows by the Indiclal Method," AIAA Journal, Vol. 16, No. 2, Feb. 1978, DP. 117-124.

8. Ashley, H., "On the Role of Shocks in the "Sub-Transontc" Flutter Phenonmenon," Journal of Alreraft, Vol. 17, No.3, Mar. 1980, DP. 187-197.

9. Yang, T.Y., Guruswamy, P., and Striz, A.G., "Application of Transonlc Codes to Flutter Analysis of Conventional and Supercritical Airfolls," Journal of Alrcraft. Vol. 19, No. 3, Mar. 1982, pp. 211-220.

10. Edwards, J.W., Bennett, R.M., Whltlow, W. Jr., and Seldel, D.A., "Tlme-Marching Transontc Flutter Solutions Including Angle-of-Attack Effects," Journal of Aircraft, Vol. 20. No. 11, Nov. 1983, pp. 899-906.

11. Ueda, T. and Dowell, E.H., "Flutter Analysts Using Nonlinear Aerodynamic Forces," Journal of Alrcraft, Vol. 21, No.2, Feb. 1984, pp. 101-109.

12. Eastep, F.E. and Olsen, J.J., "Transonic Flutter Analys /s of a Rectangular Wing with Conventional Alrfoll Sections," AIAA Journal. vol. 18. No. 10, Oct. 1980, pp. 1159-1164.

13. Borland, C.J. and Rlzzetta, D.P., "Nonlinear Transonic Flutter Analysis," AIAA Journal. Vol, 20, No. 11, Nov. 1982, pp. 1606-1615.

14. Bland, S.R. and Edwards, J.W., "Airfoll Shape and Thickness Effects on Transonic Airloads and Flutter," Journal of Aircraft, Vol. 21, No. 3. Mar. 1984, DP. 209-217.

15. Batina, J.T., "Unsteady Transonic Algorithm Improvements for Realisitc Alrcraft Applications." AIAA Paper 88-0105, Jan. 1988.

16. Magnus, R.J.. "Calculation of Some Unsteady Transonic Flows about NACA $64 A 006$ and $64 A 010$ Alrfolls," AFFOL-TR-77-46, July 1977. (Avall. NTIS, AD-A046178).
17. Davis, S.S. and Malcolm, G.N. "Transonic Shock-Wave/Boundary-Layer Interactions on an Oscillating Alrfoll," AIAA Journal, Vol. 18.

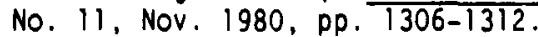

18. Batina, J.T., "Unsteady Transonic Flow Calculations for Two-Dimensional Canard-Wing Configurations with Aeroelastic Applications," 26th Structures, Structural Dynamics and Materials Conference, Part 2, AIAA, New York, 1985, pp. 1-9.

19. Borland, C.J., Rizzetta, D.P., and Yoshihara, H., "Numerical Solution of ThreeDimensional Unsteady Transonic Flow Over Swept Wings," AIAA Journal, Vol. 20, No. 3, Mar. 1982, pp. 340-347.

20. Isogai, K., "Numerical Study of Transonic Flutter of a Two-Dimensional Airfoll." NAL-TR-617T, 1980.

21. Isogai, K., "Transonic Dip Mechanism of Flutter of a Sweptback Wing, Part II, " AIAA Journal, Vol. 19, No. 9, Sept. 1981, pp. 1240-1242.

22. Yates, C.E., Jr, and Chu, L.C., "Static Aeroelastic Effects on the Flutter of a Supercritical Wing," NASA TM-89132, 1987.

23. Bendiksen, 0.0. and Kousen, K.A., "Transonic Flutter Analysis Using the Euler Equations," AIAA Paper 87-0911, Apr. 1987.

24. Wu, J.C., Kaza, K.R.V., and Sankar, L.N., A Technlque for the Prediction of Atrfoll Flutter Characteristics in Separated Flow, 28th Structures, Structural Dynamics and Materlals Conference, Part 2B, AIAA, New York, 1987, PD. 664-673.

25. Edwards, J.W. and Thomas, J.L., "Computational Methods for Unsteady Transonic Flows, "AIAA Paper 87-0107, Jan. 1987.

26. Sankar, N.L. and Tang, W., "Numerical Solution of Unsteady Viscous Flow Past Rotor Sections," AIAA Paper 85-0129, Jan. 1985.

27. Wu, J.C., "A Numerical Study of Turbulent Flow Past Alrfolls," Ph.D. Thesis, Georgia Institute of Technology, 1988.

28. Beam, R.M. and Warming, R.F., "An Implicit Factored Scheme for the Compressible NavierStokes Equations," AIAA Journal, Vol. 16, No. 4, Apr. 1978, pp. 393-402.

29. Steger, J.L., "Impliclt Finite Difference Simulation of Flow About Arbitrary Two-Dimensional Geometries," AIAA Journal, Vol. 16, No.7, July 1978, pp. $\frac{679-686 .}{6}$

30. Srinivasan, R. and McCroskey, W.J., "Numerical Simulation of Unsteady Airfoil-Vortex Interaction," Vertica, Vol. 11, No. 12, 1987, pp. 2-28.

31. Pulllam, T.H., "Artificlal Dissipation Models for the Euler Equations," AIAA Journal, Vol. 24, No. 12, Dec. 1986, pp. 1931-1940. 
32. Swanson, R.C. and Turkel, E., "Artificlal Dissipation and Central Difference Schemes for the Euler and Navier-Stokes Equations," 8 th Computational Flutd Dyanmics Conference. AIAA, New York, 1987, pp. 55-69.

33. Baldwin, 8.S. and Lomax, H., "Thin Layer Approximation and Algebraic Model for Separated Turbulent Flows," AIAA Paper 78-0257, Jan. 1978.

34. Sorenson, R.L., "A Computer Program to Generate Two-Dimensional Grids About Alrfolls and Other Shapes by the use of Possion's Equation," NASA TM-81198, 1980.
35. Chima, R.V., "Explicit Multi-Grid Algorithm for Quas I Three-Dimensional Viscous Flows in Turbomachinery," Journal of Propulsion and Power, Vol. 3, No. 5, Sept.-Oct. 1987. pp. 397-405.

36. Huff, D.L., Wu, J.C., and Sankar, L.N., "Analysis of Viscous Transonlc Fiow Over Alrfoll Sections," AIAA Paper 87-0420, Jan. 1987. (NASA TM-88912).

37. Bland, S.R., "Development of Low-Frequency Kernel-Function Aerodynamics for Comparison with Time-Depenedent Finite-Difference Methods," NASA TM-83283, 1982.

\section{Table 1. - STRUCTURAL PARAMETERS}

USEO IN THE STUDY

[Distances are nondimensionalized

with respect to semi-chord (b). see Fig. I (a) for definitions.j

\begin{tabular}{|l|c|c|}
\hline Parameter & Case A & Case B \\
\hline $\mathrm{ah}_{h}$ & -2 & -1 \\
$\omega_{h} / \omega_{\alpha}$ & 1 & 0.928 \\
$\mathrm{x}_{\alpha}$ & 1.8 & 0.9644 \\
$\mathrm{r}_{\mathrm{cg}}$ & 0.4898 & 0.4769 \\
$\mu$ & 60 & 115 \\
$\zeta_{h}, \zeta_{\alpha}$ & 0 & 0 \\
\hline
\end{tabular}




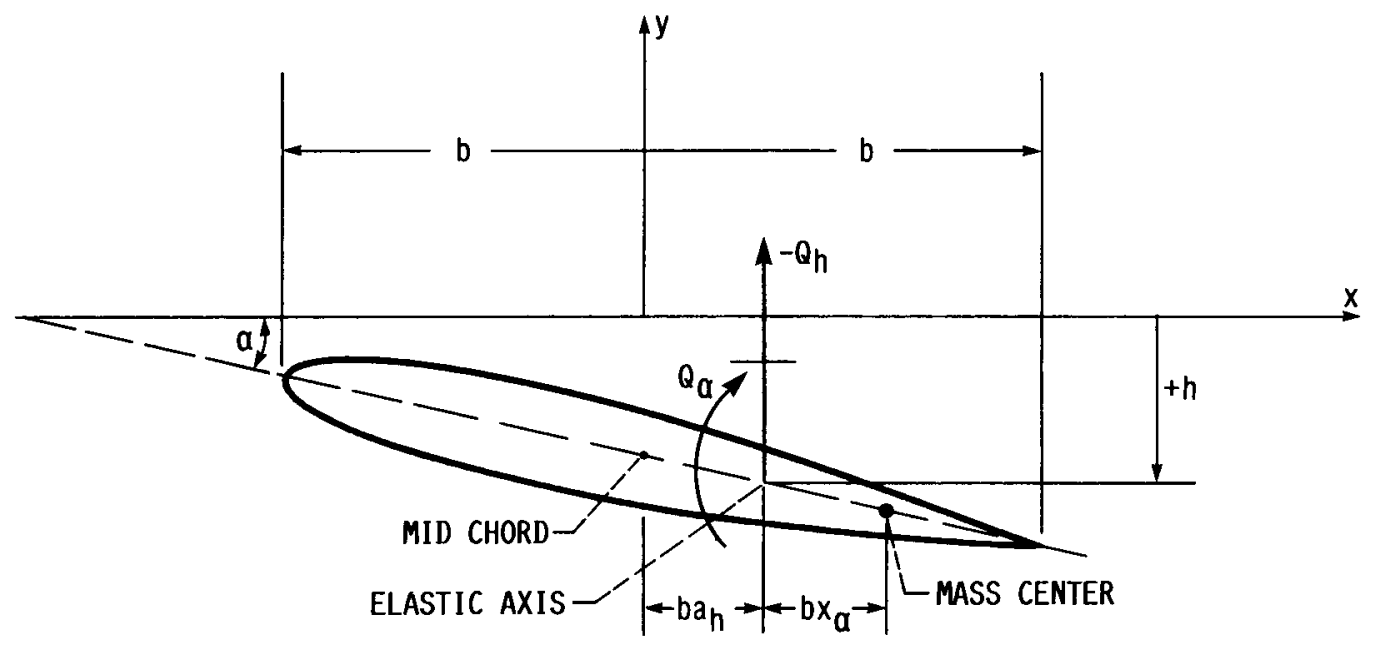

(A) TWO-DEGREES OF FREEDOM TYPICAL SECTION MODEL.
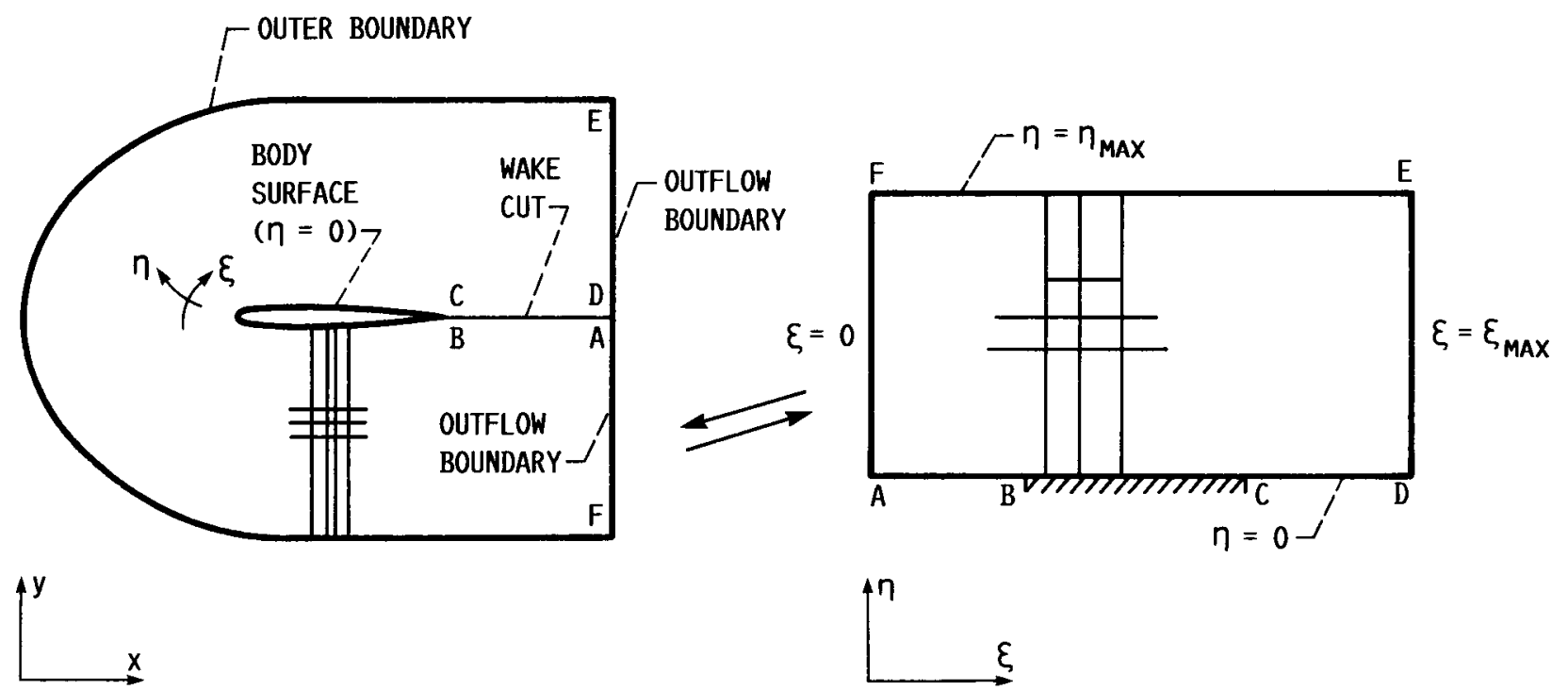

(B) PHYSICAL AND COMPUTATIONAL DOMAINS.

FIGURE 1. - COORDINATE SYSTEMS FOR STRUCTURAL AND AERODYNAMIC MODELS. 


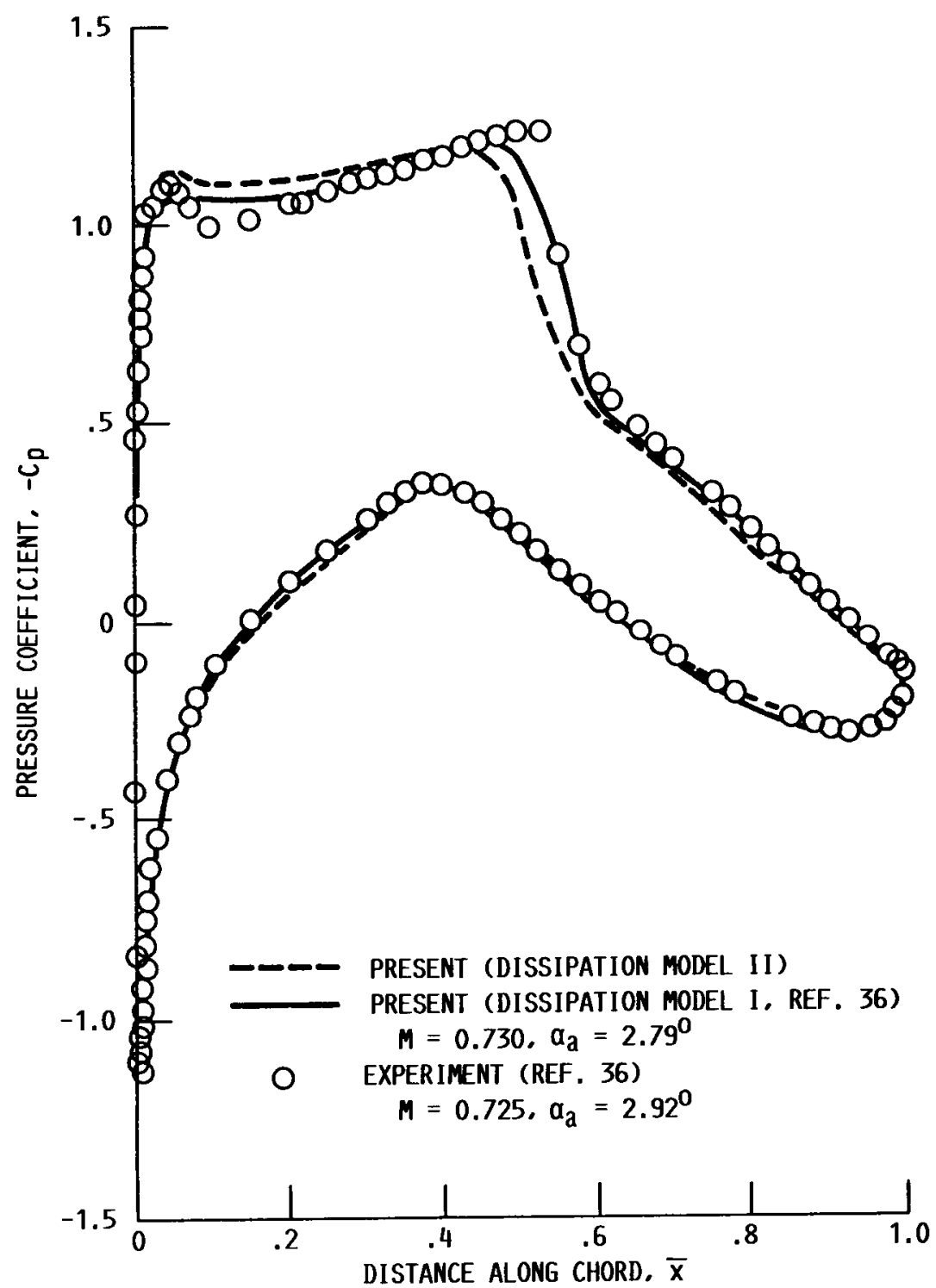

FIGURE 2. - PRESSURE DISTRIBUTIONS FOR RAE 2822 AIRFOIL. $\mathrm{RE}=6.50$ MILLION. (157×58 NUMERICAL C-GRID. $)$ 


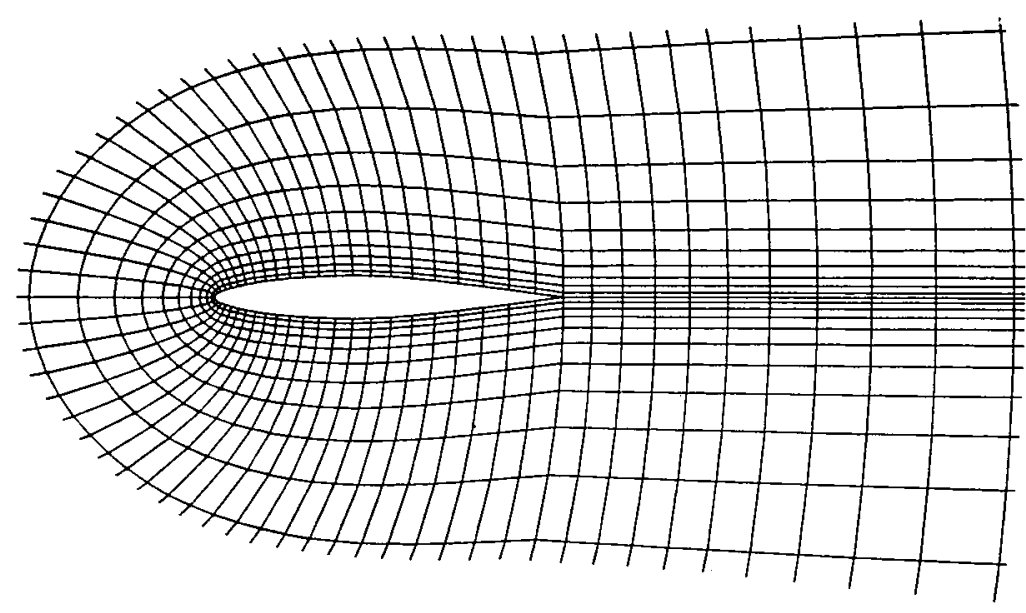

FIGURE 3. - PORTION OF AN ALGEBRAIC C-GRID SYSTEM AROUND NACA $64 A 010$ AIRFOIL.

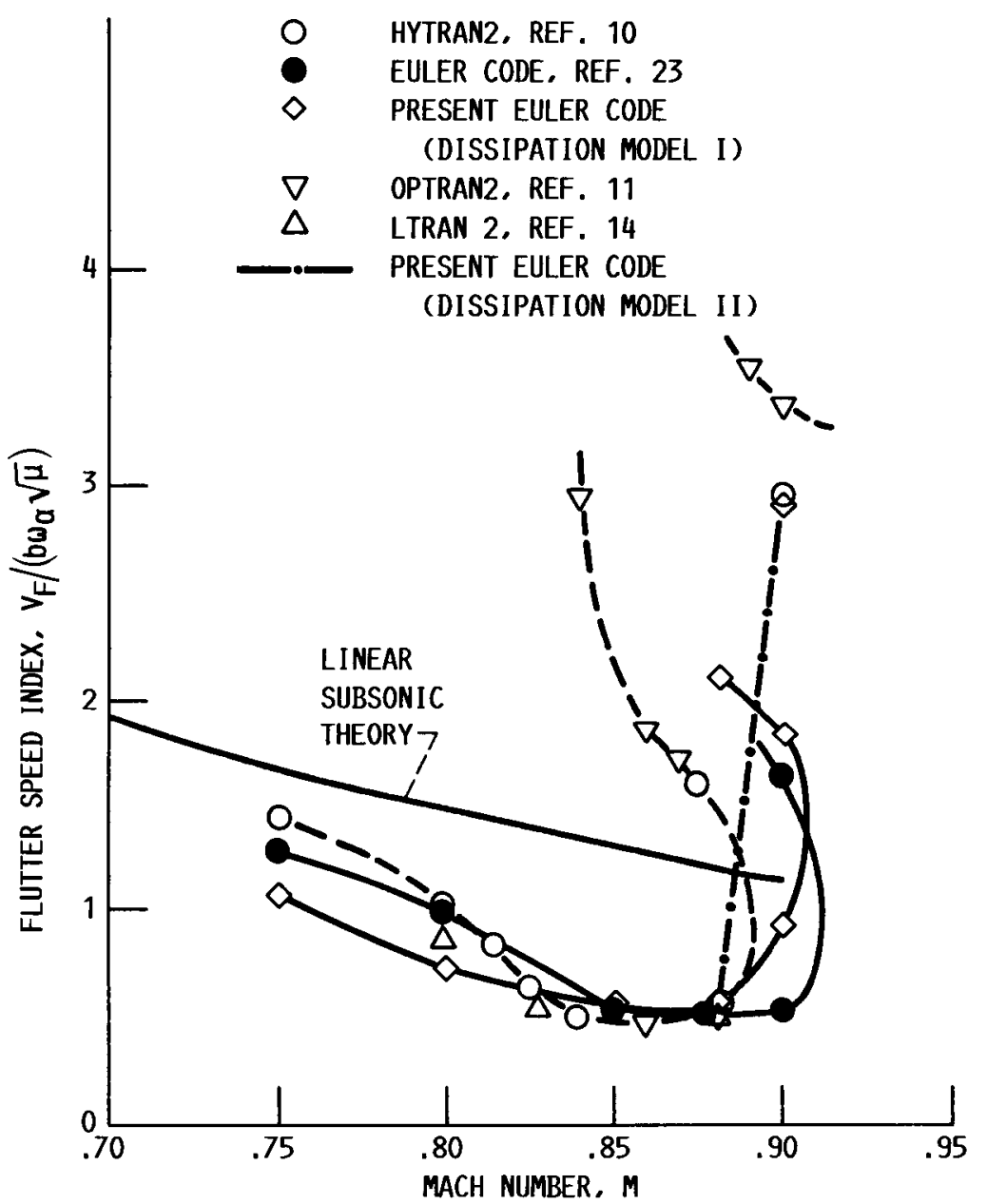

FIGURE 4. - FLUTTER BOUNDARIES FOR THE NACA 64 A010 AIRFOIL. (CASE A, TABLE 1.) 


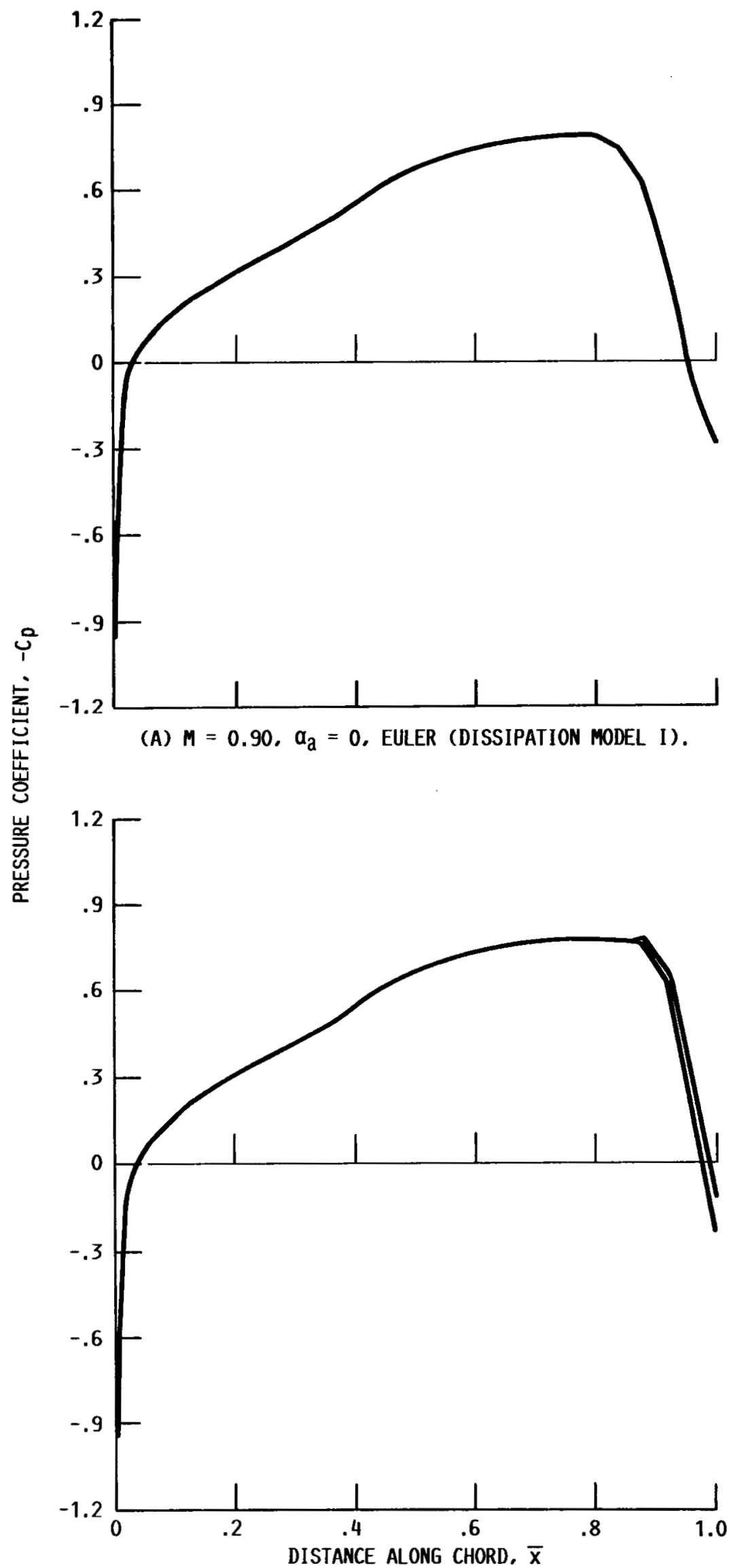

(B) $M=0.90, \alpha_{a}=0$. EULER (DISSIPATION MODEL II).

FIGURE 5. - STATIC PRESSURE DISTRIBUTION, NACA 64A010 AIRFOIL.

14 


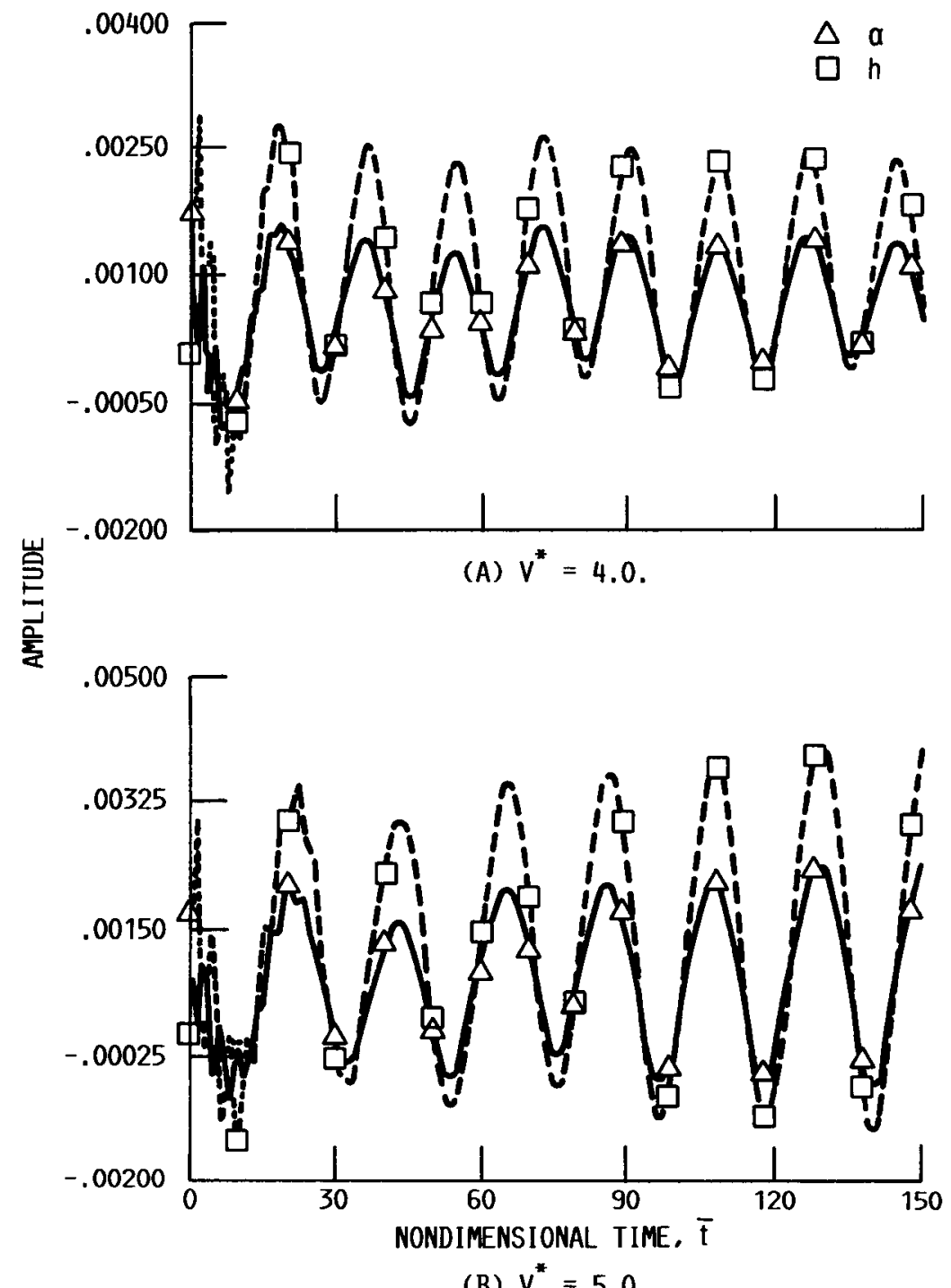

(B) $v^{*}=5.0$.

FIGURE 6. - PLUNGING AND PITCHING AMPLITUDES VERSUS

TIME, NACA 64A010 AIRFOIL, $M=0.88, a_{h}=-2.0$.

$\omega_{h} / \omega_{a}=1.0, x_{a}=1.8, r_{a}=1.865$, EULER, ALGE-

BRAIC C-GRID (157 $\times 40)$. 




FIGURE 7. - FLUTTER BOUNDARIES FOR THE NACA $64 A 010$ AIRFOIL. (CASE A, TABLE 1.) 


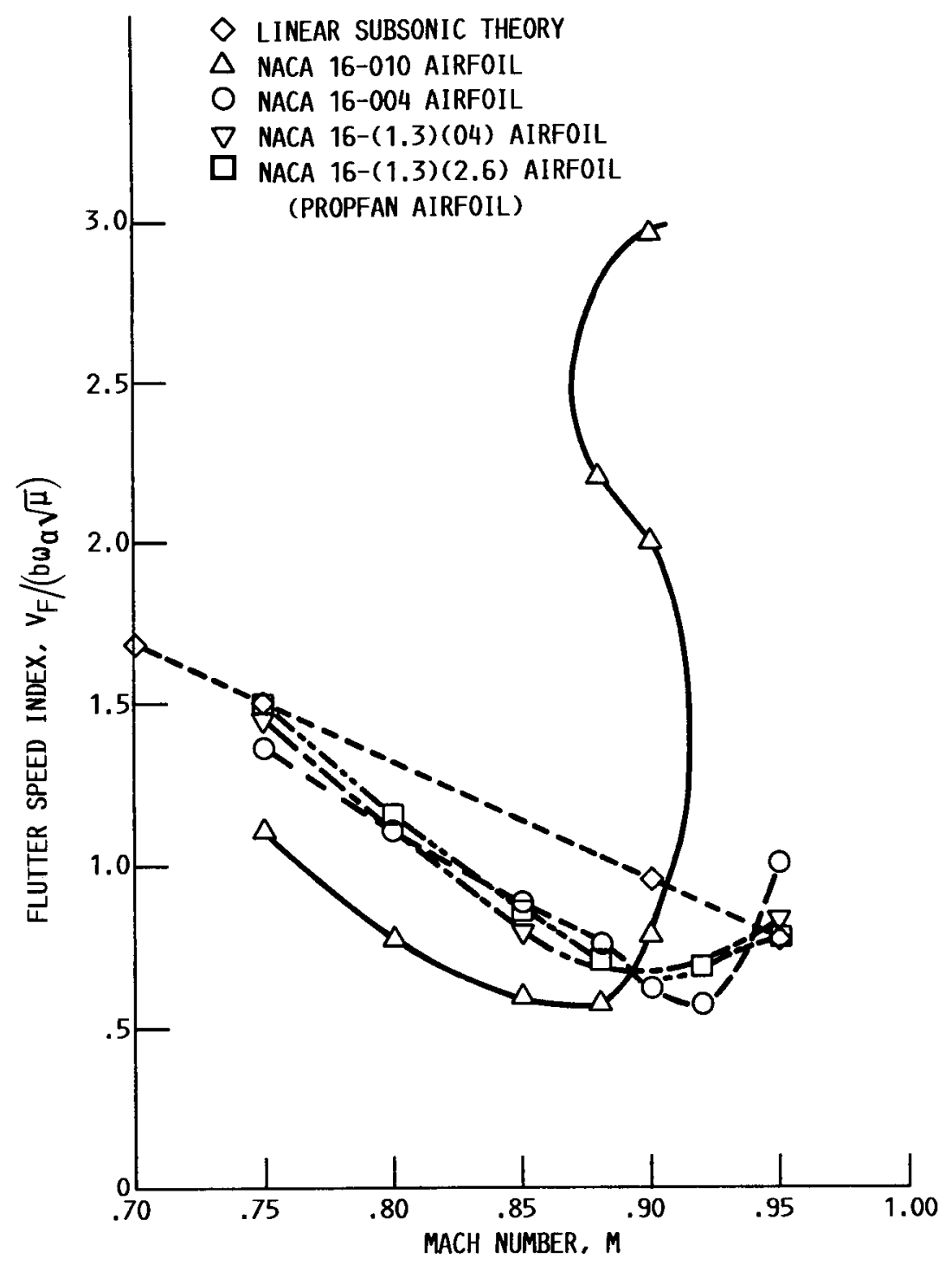

FIGURE 8. - FLUTTER BOUNDARIES FOR FOUR AIRFOILS.

(CASE A, TABLE 1, DISSIPATION MODEL I.) 


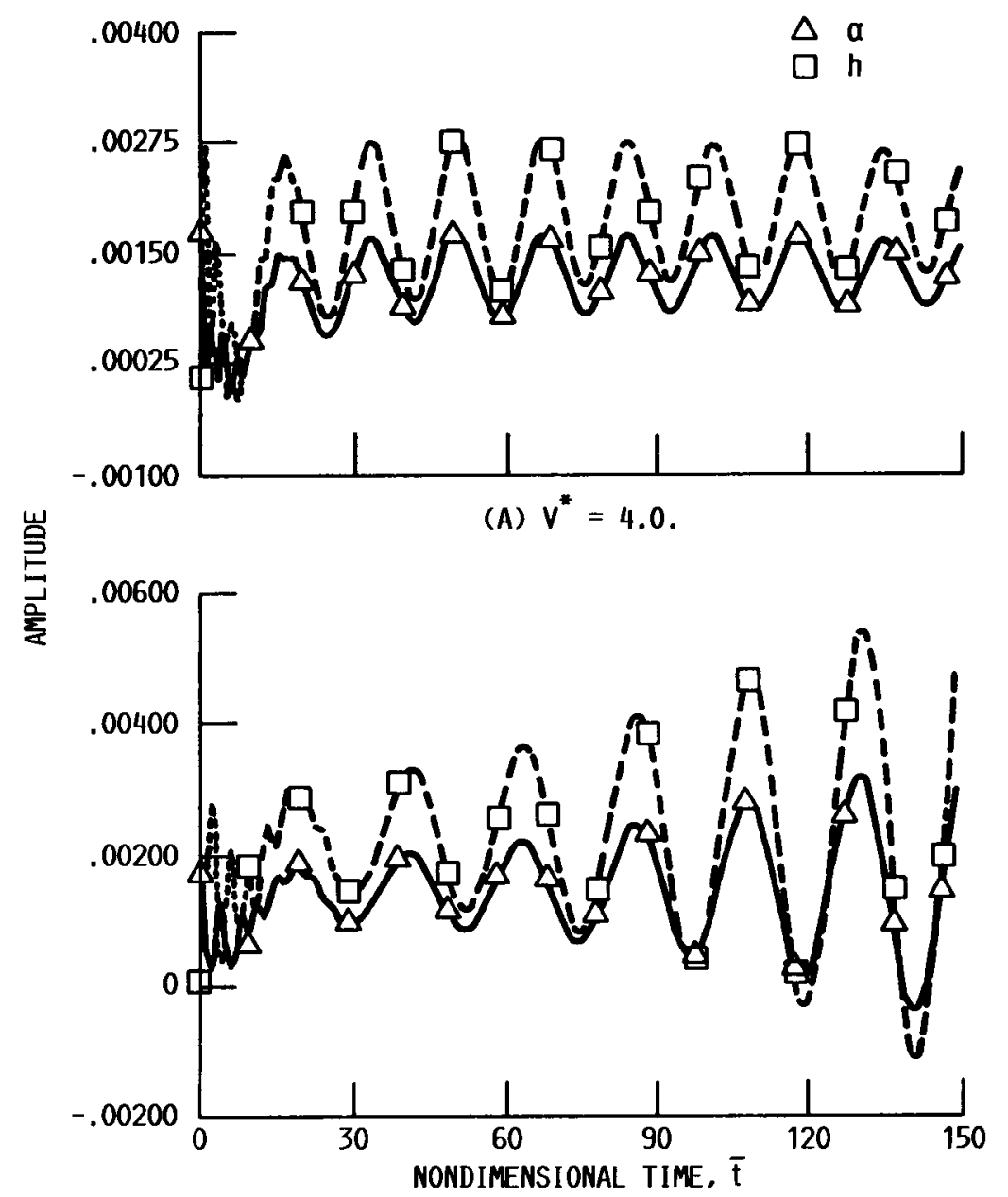

(B) $V^{*}=6.0$.

FIGURE 9. - PLUNGING AND PITCHING AMPLITUDES VERSUS TIME, NACA 16-004 AIRFOIL, $M=0.92, a_{h}=-2.0$. $\omega_{h} / \omega_{a}=1.0, x_{a}=1.8, r_{a}=1.865$, EULER, ALGEBRAIC C-GRID (157 $\times 40)$. 


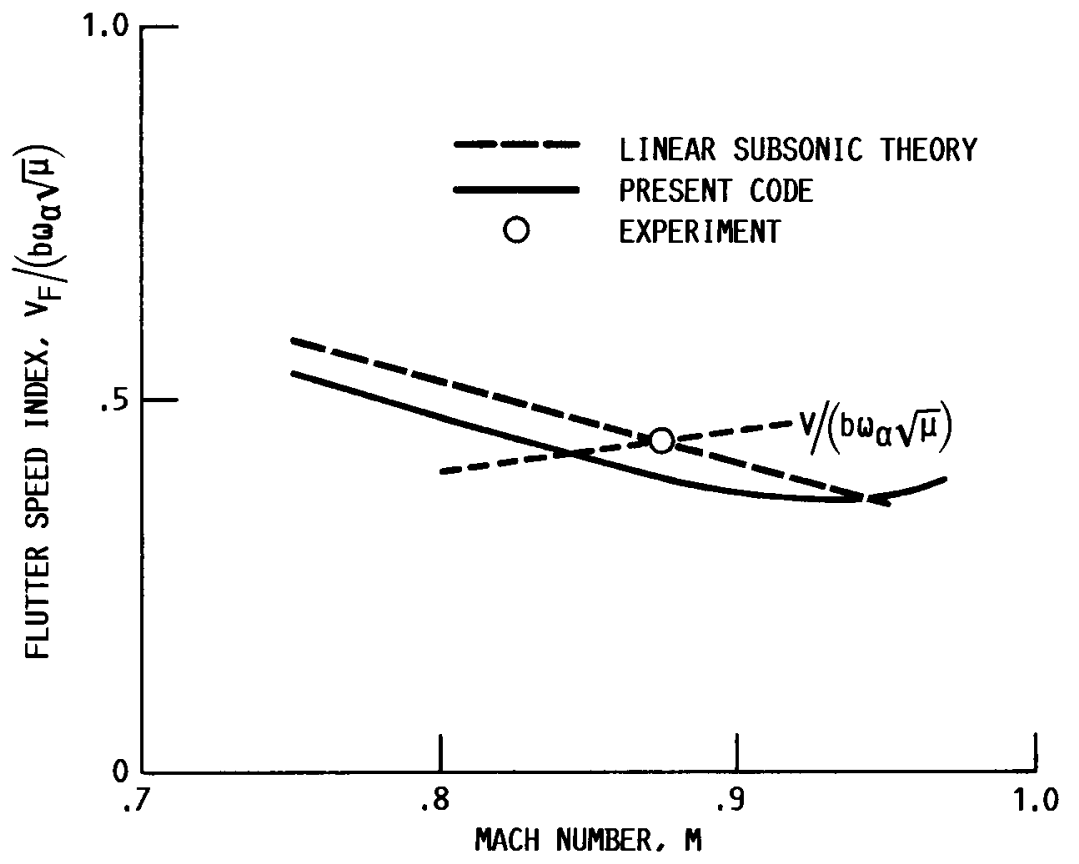

FIGURE 10. - FLUTTER BOUNDARY FOR SR5 PROPFAN SIMULATED TYPICAL SECTION MODEL. (CASE B, TABLE 1, DISSIPATION MODEL I.) 


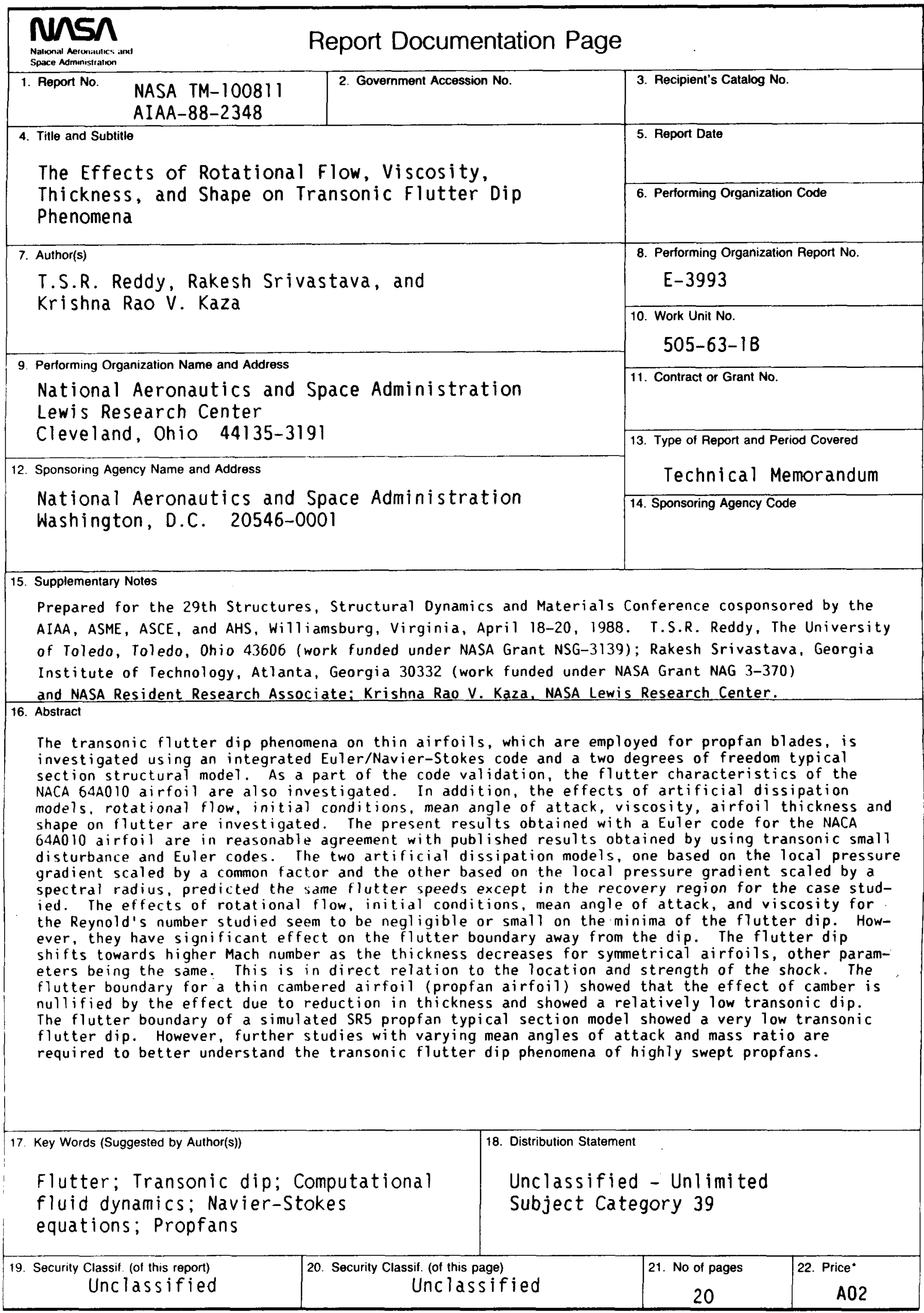

